\title{
Evaluating the vertical HIV transmission risks among South African female sex workers; have we forgotten PMTCT in their HIV programming?
}

Jean Olivier Twahirwa Rwema ${ }^{*}$, Stefan Baral ${ }^{1}$, Sosthenes Ketende ${ }^{1}$, Nancy Phaswana-Mafuya ${ }^{3,4}$, Andrew Lambert ${ }^{2}$, Zamakayise Kose ${ }^{3}$, Mfezi Mcingana ${ }^{5}$, Amrita Rao ${ }^{1}$, Harry Hausler ${ }^{2}$ and Sheree Schwartz ${ }^{1}$

\begin{abstract}
Background: Female sex workers (FSW) have a greater HIV burden compared to other reproductive-aged women and experience high incidence of pregnancies. However, there are limited data on mother-to-child transmission of HIV in the context of sex work. This study assessed the uptake of prevention of mother-to-child transmission (PMTCT) services to understand the vertical HIV transmission risks among FSW in South Africa.

Methods: FSW $\geq 18$ years were recruited into a cross-sectional study using respondent-driven sampling (RDS) between October 2014-April 2015 in Port Elizabeth, South Africa. An interviewer-administered questionnaire captured information on demographics, reproductive health histories, and HIV care, including engagement in PMTCT care and ART. HIV and pregnancy testing were biologically assessed. This analysis characterizes FSW engagement in HIV prevention and treatment cascades of the four prongs of PMTCT.

Results: Overall, 410 FSW were enrolled. The RDS-weighted HIV prevalence was 61.5\% (95\% bootstrapped confidence interval 54.1-68.0). A comprehensive assessment of the four PMTCT prongs showed gaps in cascades for each of the prongs. In Prongs 1 and 2, gaps of 42\% in consistent condom use with clients among HIV-negative FSW and 43\% in long-term high efficacy contraceptive method use among HIV-positive FSW were observed. The analyses for prongs three and four pertained to 192 women with children < 5 years; 101/192 knew their HIV diagnosis prior to the study, of whom $85 \%(86 / 101)$ had their children tested for HIV after birth, but only 36\% (31/86) of those who breastfed retested their children post-breastfeeding. A substantial proportion (35\%, 42/120) of all HIV-positive women with children $<5$ years of age were HIV-negative at their last delivery and seroconverted after delivery. Less than half (45\%) of mothers with children $<5$ years (45/101) were on ART and $12 \%(12 / 101)$ reported at least one child under five living with HIV.

Conclusion: These findings show significant gaps in engagement in the PMTCT cascades for FSW, evidenced by sub-optimal uptake of HIV prevention and treatment in the peri/post-natal periods and insufficient prevention of unintended pregnancies among FSW living with HIV. These gaps result in elevated risks for vertical transmission among FSW and the need for PMTCT services within FSW programs.
\end{abstract}

Keywords: PMTCT, Vertical transmission, Female sex workers, South Africa

\footnotetext{
* Correspondence: jtwahir1@jhu.edu; jtwahir1@jhmi.edu

${ }^{1}$ Department of Epidemiology, Key Populations Program, Center for Public

Health and Human Rights, Johns Hopkins Bloomberg School of Public

Health, 615 N Wolfe Street, Baltimore, MD 21205, USA

Full list of author information is available at the end of the article
}

(c) The Author(s). 2019 Open Access This article is distributed under the terms of the Creative Commons Attribution 4.0 International License (http://creativecommons.org/licenses/by/4.0/), which permits unrestricted use, distribution, and reproduction in any medium, provided you give appropriate credit to the original author(s) and the source, provide a link to the Creative Commons license, and indicate if changes were made. The Creative Commons Public Domain Dedication waiver (http://creativecommons.org/publicdomain/zero/1.0/) applies to the data made available in this article, unless otherwise stated. 


\section{Background}

In 2011, the global plan towards the elimination of new HIV infections among children was launched with a target of reducing new HIV infections among children by $90 \%$ by 2015 [1]. Given that vertical mother-to-child transmission (MTCT) comprises more than 90\% of pediatric HIV infections, the plan focused on the WHO's comprehensive approach to the prevention of motherto-child transmission of HIV (PMTCT). The fourpronged approach includes primary prevention of HIV infection among women of childbearing age, prevention of unintended pregnancies among women living with HIV, prevention of HIV transmission from women living with HIV to their children, and providing appropriate treatment, care and support to women and children living with HIV and their families [2]. The plan focused on 22 priority countries, of which 21 were from sub-Saharan Africa (SSA), and had a target to reduce vertical transmission to under 5\% among breastfeeding women and to less than $2 \%$ among non-breastfeeding women [1-3].

By the end of 2015, South Africa reduced the number of new pediatric HIV infections by $84 \%$ and achieved a MTCT target rate of $2 \%$ [3]. Despite successful implementation of the PMTCT program in South Africa and ART uptake among pregnant women living with HIV surpassing 90\%, neither South Africa nor other high performing PMTCT countries met the targets for reduction in overall pediatric infections $[3,4]$. Analyses have highlighted that most of the PMTCT programming focus was put on prongs three and four, leaving the first two behind. For instance, there was a reduction of just $6 \%$ of new HIV infections among women of reproductive age, far below the $50 \%$ target [3]. Significant gaps also remain in the sexual and reproductive health and rights (SRHR) programming evidenced by unmet needs for family planning among women living with HIV [5]. Lastly, health disparities among specific populations, including female sex workers (FSW), result in unequal access to SRHR, HIV prevention, and HIV treatment services which may result in pockets of risk for vertical transmission for which programming efforts are currently insufficient [6].

FSW are disproportionately affected by HIV compared to other women of reproductive age in SSA [7-9]. Structural factors including stigma, discrimination, criminalization and gender-based violence put FSW at a heightened risk for HIV acquisition and transmission, while limiting FSW engagement in HIV prevention and treatment services $[10,11]$. Despite the prevention and treatment needs faced by FSW, few data are available on FSW engagement in PMTCT services. FSW experience a high incidence of pregnancy and the majority are mothers; yet MTCT risks and outcomes of FSW living with HIV in SSA are largely unknown [6]. This is true in South Africa as well, where despite remarkable scale-up of the national PMTCT program, there is little knowledge of PMTCT engagement and outcomes among the FSW population.

The objective of this paper is to utilize an HIV prevention cascades framework to characterize engagement in the four prongs of the PMTCT approach among FSW in Port Elizabeth, South Africa, to assess vertical transmission risks among FSW.

\section{Methods \\ Study design and population}

Data for this analysis are from a cross-sectional study to describe HIV prevalence and MTCT risks among FSW from Port Elizabeth and the greater Nelson Mandela Bay Metropolitan Municipality (NMBM) in South Africa. FSW were recruited using respondent-driven sampling (RDS) from October 2014 to April 2015. RDS is a method to sample hidden populations like FSW by involving peers to recruit in their networks [12]. The study setting and design have been described previously [13, 14]. Briefly, nine FSW were recruited as "seeds" to recruit their peers. Each "seed" was given three referral coupons to recruit other FSW in her network into the study. Eligible participants were cisgender women who were at least 18 years old, possessing a valid study coupon, living in the NMBM and reporting sex work as their main source of income in the year preceding the study. Consideration was made in the selection of the "seeds" to ensure diversity in HIV status, race, age and location. Prior to enrolment, a short eligibility assessment was conducted by study interviewers using a structured questionnaire. Following eligibility screening, eligible women completed written informed consent in English or Xhosa prior to study enrollment. Each participant was in turn given three coupons to recruit in their network as well. Participants received reimbursement for their transport and time up to a total of US\$10 for their study visit and successful recruitment of up to three FSW.

During the study, structured face-to-face interviews were conducted by trained data collectors using a standard questionnaire. Information on sociodemographic characteristics, reproductive health history, knowledge and attitudes regarding HIV and STI risk, practices with paying and nonpaying sexual partners was collected.

Rapid HIV and urine pregnancy tests were performed for all participants. HIV testing followed South African HIV testing guidelines [15]. Viral load testing was conducted at the local reference laboratory for women who were pregnant and living with HIV at the time of the study.

The study was approved by the institutional review boards of Johns Hopkins School of Public Health and the Human Sciences Research Council in South Africa. 


\section{Statistical analyses}

Descriptive statistics of participant sociodemographic and SRHR characteristics are presented as crude proportions and RDS-weighted estimates.

Engagement in PMTCT services was assessed by performing a cascade analysis for all four PMTCT prongs. PMTCT cascades have been used extensively in the literature as tools to evaluate the implementation and performance of PMTCT programs in different countries [16-18]. For prong one, primary prevention of HIV infection among women of childbearing age, we assessed consistent condom use (CCU) among HIV negative FSW by type of sexual partner, including regular and new clients, casual and long-term nonpaying partners. CCU was defined as using condoms during all their 10 most recent vaginal or anal sexual acts. Only CCU was considered for primary prevention of HIV because PrEP was recommended for FSW after data collection for this study was completed [19]. For the second prong, prevention of unintended pregnancies among women living with HIV, we assessed the use of contraception methods among FSW who were living with HIV and not trying to get pregnant at the time of study. Contraceptive use was sub-divided into two categories: use of any form of contraception, and use of more reliable long-term, non-barrier contraception methods. For the former, self-report of any of the following was assessed: condom use for family planning, birth control pill, intrauterine device (IUD), injectable birth control (Depo Provera or Nuristerate), implant (Norplant or Jadelle), diaphragm or cervical cap and tubal ligation. For longterm methods, we included the IUD, implant, injectable and tubal ligation. For prongs 3 and 4, prevention of HIV transmission from women living with HIV to their children and provision of appropriate treatment, care and support to women and children living with HIV and their families, analyses were restricted to HIV positive FSW who had children under 5 years of age to place the findings in the current PMTCT context. We used two PMTCT cascade analyses for these mothers and their infants. Prongs 3 and 4 were assessed using combined cascades, one based on engagement of mothers and the other on data regarding their children. The steps in the mothers' cascade evaluated information on the mothers' HIV and treatment status during pregnancy and in the years following pregnancy. Although current HIV status was biologically confirmed, HIV status during pregnancy was self-reported. The cascade for children was restricted to children born to mothers with a known HIV diagnosis prior to the study. The proportion of infants tested for HIV at least once after delivery was evaluated, along with those retested post breastfeeding and the vertical transmissions reported by mothers. All the analyses were performed with Stata Version 14.2 (StataCorp, College Station, TX).

\section{Results}

A total of 1069 coupons were distributed by the study, of which 435 women presented to the study site. It is unknown how many of the 1069 coupons were distributed by FSW participants to other FSW. Overall, 25 did not meet the eligibility criteria and 410 including the nine seeds met the eligibility criteria and were enrolled in the study. The median number of RDS recruitment waves was 6 (IQR:4-9) while the maximum attained was 16. The median age was 28 years (IQR:19-51). Of them, $42 \%(172 / 410)$ were single, $84 \%(343 / 410)$ had been pregnant at least once and $75 \%(307 / 410)$ had at least one biological child. The majority, 70.6\% [(243/343); RDS adjusted prevalence: $66.4 \%(95 \%$ CI: $58.1-74.8)]$, of FSW who had previously been pregnant reported a past unintended pregnancy. The crude HIV prevalence was 63.7\% (95\%CI: 59.0-68.3); the RDS-weighted estimate was 61.5\% (95\% bootstrapped confidence interval 54.1-68.0). Crude and RDS-adjusted estimates of socio-demographic and other characteristics are summarized in (Table 1).

Regarding engagement in ANC and delivery services, 95\% (183/192) of FSW reported at least one ANC visit and $94 \%(181 / 192)$ had been offered HIV testing services during ANC. Twenty-eight percent (54/192) of FSW were asked by a provider to bring a partner during their ANC visit and 2 of them reported to have ever been denied ANC services because their male partners had not attended. All FSW (100\%) reported to have delivered at a healthcare facility.

Regarding sex work dynamics during pregnancy, among mothers engaged in sex work prior to pregnancy, women reported continuing sex work for a median of 5 months IQR [4-7] during pregnancy following pregnancy diagnosis. When considering return to sex work following pregnancy, 27\% (38/143) had resumed sex work within the first 3 months after delivery, increasing to $48 \%(69 / 143)$ by sixth months post-partum.

\section{Engagement in the PMTCT cascade}

At the time of the study, 5\% (19/410) of all FSW were pregnant. Among pregnant FSW, 68\% (13/19) were HIV positive, $31 \%(4 / 13)$ of whom were on ART. Viral load assessments among HIV positive pregnant women indicated that none of the pregnant FSW living with HIV were virally suppressed (Fig. 1). In terms of engagement in the four prongs of the PMTCT approach, primary prevention of HIV among women of childbearing age (Prong 1) was assessed. Among HIV negative FSW, CCU in the last 10 sexual acts was 58\% (84/145) with paying clients, $21 \%(4 / 19)$ with casual nonpaying partners and 10\% (8/77) with long-term partners (Fig. 2). 
Table 1 Sociodemographic and reproductive health characteristics of participating female sex workers in Port Elizabeth, South Africa, 2014-2015

\begin{tabular}{|c|c|c|c|}
\hline Characteristic & $\mathrm{N}$ & Crude \% & RDS-Adjusted \% [95\% CI] \\
\hline \multicolumn{4}{|l|}{ Age } \\
\hline $18-24$ & 122 & 29.8 & $38.2(30.1-46.3)$ \\
\hline $25-34$ & 205 & 50 & $44.0(37.0-51.0)$ \\
\hline$>35$ & 83 & 20.2 & $17.8(12.2-23.5)$ \\
\hline \multicolumn{4}{|l|}{ Race } \\
\hline Black African & 337 & 83.2 & $74.5(60.6-88.4)$ \\
\hline Other & 68 & 16.8 & $25.5(11.6-39.4)$ \\
\hline \multicolumn{4}{|l|}{ Education } \\
\hline 0 - 8 th grade & 87 & 21.2 & $22.9(17.2-28.5)$ \\
\hline Some secondary school & 158 & 38.5 & $36.5(30.5-42.5)$ \\
\hline Secondary level or above & 165 & 40.3 & $40.6(33.9-47.3)$ \\
\hline \multicolumn{4}{|l|}{ Relationship status } \\
\hline Single & 172 & 42.0 & $39.7(32.9-46.4)$ \\
\hline In relationship with steady partner & 238 & 58.0 & $60.3(53.6-67.1)$ \\
\hline \multicolumn{4}{|l|}{ History of pregnancy } \\
\hline Never been pregnant & 67 & 16.3 & $15.9(11.7-20.3)$ \\
\hline Has been pregnant at least once & 343 & 83.7 & $84.1(79.7-88.3)$ \\
\hline \multicolumn{4}{|c|}{$\begin{array}{l}\text { History of unintended pregnancy among FSW with a } \\
\text { history of pregnancy }\end{array}$} \\
\hline Never & 100 & 29.3 & $33.5(25.2-41.9)$ \\
\hline Has had at least one unintended pregnancy & 243 & 70.6 & $66.4(58.1-74.8)$ \\
\hline \multicolumn{4}{|l|}{ Biological children } \\
\hline Has no child & 103 & 25.1 & $24.8(19.3-30.4)$ \\
\hline Has at least one child & 307 & 74.9 & $75.2(69.6-80.7)$ \\
\hline \multicolumn{4}{|l|}{ Average income per week } \\
\hline Less than 500 ZAR & 151 & 36.8 & $37.1(30.1-43.3)$ \\
\hline Over 500 ZAR & 259 & 63.2 & $62.9(56.7-69.3)$ \\
\hline \multicolumn{4}{|l|}{ Occupation } \\
\hline Sex work only & 391 & 95.4 & $93.7(89.7-97.7)$ \\
\hline Additional occupation & 19 & 4.6 & $6.3(2.3-10.2)$ \\
\hline \multicolumn{4}{|l|}{ STI symptoms in the last year } \\
\hline No & 255 & 62.2 & $63.4(56.4-70.5)$ \\
\hline yes & 155 & 37.8 & $36.6(30.1-43.2)$ \\
\hline \multicolumn{4}{|l|}{ HIV infection } \\
\hline Negative & 149 & 36.3 & $38.5(31.2-45.8)$ \\
\hline Positive & 261 & 63.7 & $61.5(54.2-68.8)$ \\
\hline
\end{tabular}

The second prong considered prevention of unintended pregnancies among women living with HIV. Of the 261 HIV positive women in the study, 22 were trying to become pregnant at the time of the study and were excluded from the prong 2 analysis. Among the remaining 239 FSW, 91\% (217/239) reported using at least one contraception method. Utilization dropped to $57 \%$ (137/239) for long-term, high efficacy contraceptive methods, (Fig. 3).
When considering engagement in treatment among FSW mothers living with HIV with children under 5 years, and child testing and treatment outcomes (Prongs 3 and 4), 192 women had children under five. From the HIV testing performed by the study, 63\% (120/192) of mothers were found to be HIV positive. The majority $(101 / 120,84 \%)$ of mothers were aware of their HIV positive status prior to the study. Among the HIV positive mothers with children under five, $65 \%(n=78 / 120)$ were 


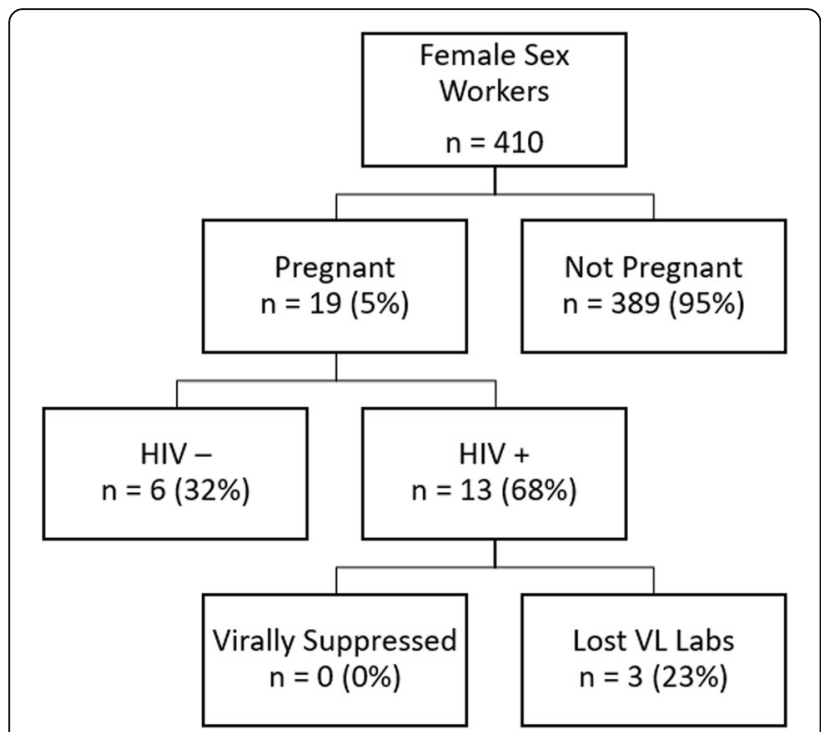

Fig. 1 Pregnancy and HIV status at the time of the study among female sex workers in Port Elizabeth, South Africa, 2014-2015

HIV positive at the time of their last delivery, while $35 \%$ (42/120) of the HIV positive mothers acquired the infection in the post-natal period. Of those who were living with HIV during pregnancy, 50\% (39/78) had started ART by the time of delivery. Overall, among all mothers living with HIV with children under five, 45\% (45/101) were on ART (Fig. 4).

Of the 101 women who were known to be living with HIV prior to the study, $85 \%(86 / 101)$ had their children tested for HIV at least once after birth. The majority (85\%, $n=86)$ of mothers breastfed, of which $36 \%(31 / 86)$ had their children retested after breastfeeding cessation. Overall, $12 \%(12 / 101)$ of previously diagnosed mothers reported at least one child under five living with HIV (Fig. 5).

\section{Discussion}

Taken together these data provide evidence of the suboptimal engagement of FSW in the PMTCT care continuum that is evidenced by significant gaps in each of the four prongs of the WHO recommended PMTCT approach. Notable gaps observed included inconsistent condom use with both clients and non-paying partners among HIV negative FSW, low uptake of more reliable contraceptive methods among HIV positive FSW, insufficient ART coverage among FSW mothers living with $\mathrm{HIV}$, and low retesting rates after breastfeeding. Vertical transmission risks were further evidenced from the infections reported by mothers, as $12 \%$ reported at least one child living with HIV.

The high levels of HIV acquisition among mothers in the months and years after delivery, 35\% of observed infections occurred among recent mothers, provides additional evidence of the need to enhance HIV prevention efforts throughout the breastfeeding period and beyond. Protecting both the mother and the child during this period are critical given that nearly $50 \%$ of FSW resumed sex work within the 6 months after delivery. The high risk of HIV acquisition in the post-partum years highlights the need for improved attention to Prong one of the PMTCT approach and expanded primary prevention efforts for new mothers, including promotion of consistent condom use but also pre-exposure prophylaxis (PrEP). Furthermore, the South African PMTCT guidelines propose repeat HIV testing for HIV negative women during pregnancy and in the post-partum period [4]. Given the frequent postnatal HIV seroconversions among FSW, the elevated MTCT risks associated with seroconversion during pregnancy [20], promoting repeat testing among pregnant and breastfeeding FSW may be particularly important to allow for early detection of new HIV infections and early initiation of treatment [21]. PrEP use

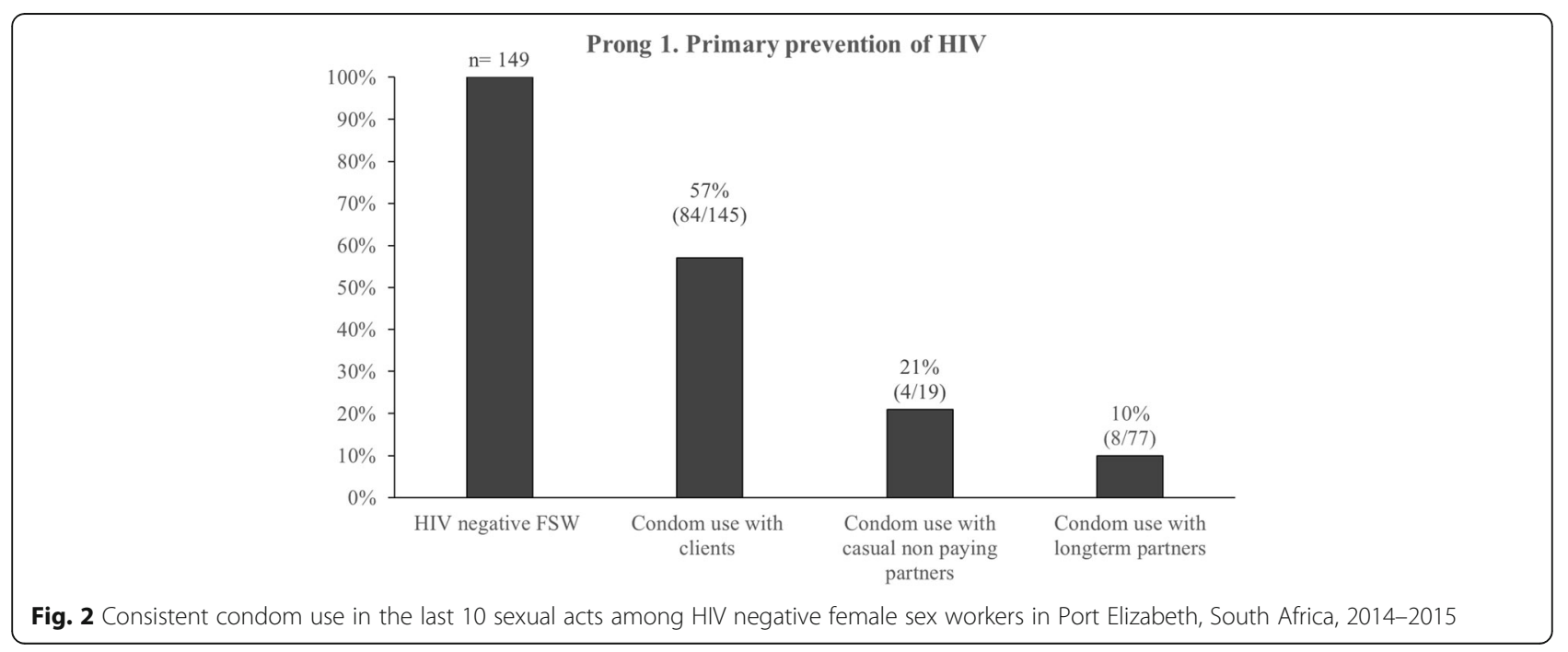


Prong 2. Prevention of unintended pregnanices among women

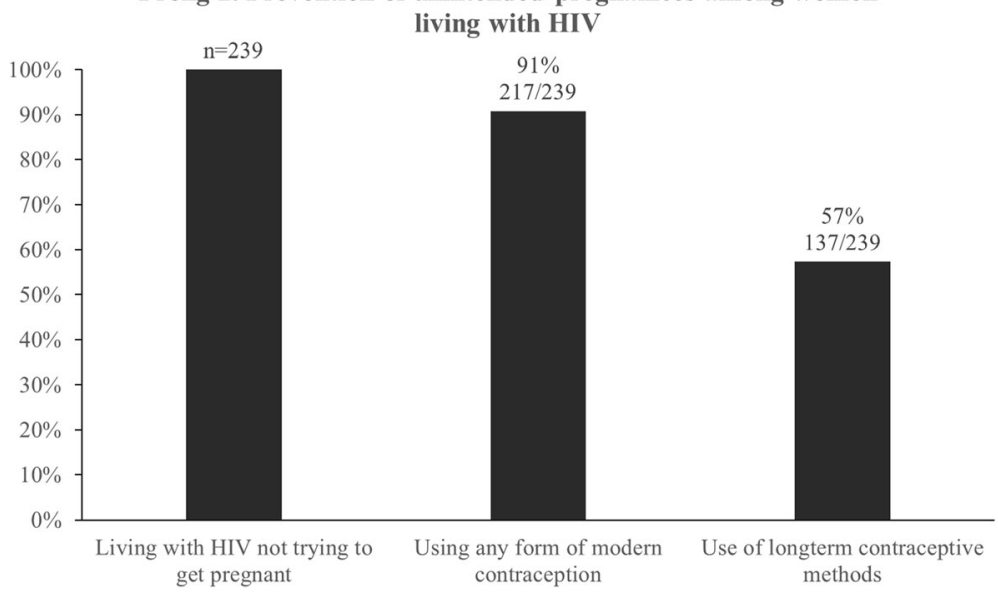

Fig. 3 Modern contraceptive use among FSW living with HIV in Port Elizabeth, South Africa, 2014-2015

for pregnant and breastfeeding FSW could also be encouraged, given favorable safety findings to date and that is a current WHO recommendation [22-24].

Although any contraceptive use among FSW living with HIV was high, just over half of FSW reported use of long-term non-barrier contraceptive methods. This is critical given the high proportion of unintended pregnancies reported among FSW in this and prior studies [25-27]. Similar patterns were found among FSW in India, Kenya, Mozambique and South Africa [28]. Further efforts to improve more reliable contraceptive use among FSW are necessary given the high rates of unplanned pregnancies and the associated adverse outcomes including late ANC consultation and low birth weight of children [29-31]. Additionally, unintended pregnancies among FSW are also associated with social and economic consequences, including decreased ability to work and loss of income [26].
A key contribution of this work is to provide an understanding of vertical transmission risks among FSW living with HIV. ART uptake during pregnancy and the post-partum period was a critical gap observed among FSW mothers. Only $50 \%$ of FSW living with HIV started ART during pregnancy and less than half of FSW with children under five were on ART at the time of the study. In comparison, overall uptake of ART treatment among all pregnant women living with HIV in South Africa is 90\% [3]. The low ART coverage among FSW has been observed in other studies, however, these data further showcase the inadequacy of routine PMTCT services for FSW. In fact, nearly all FSW with children under five attended ANC services, were offered HIV testing services during their pregnancy, but were not linked to care and treatment services. This demonstrates that despite successful PMTCT scale up in South Africa, health disparities exist in PMTCT coverage among FSW.

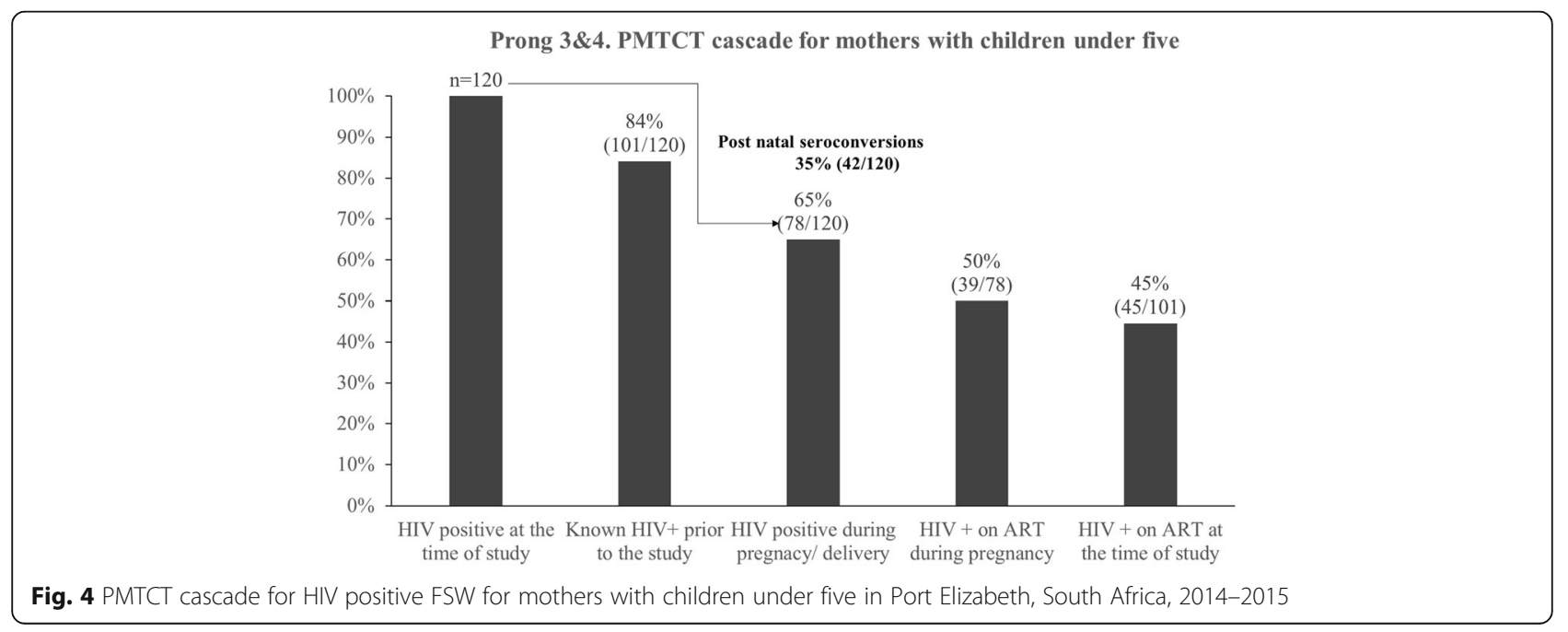




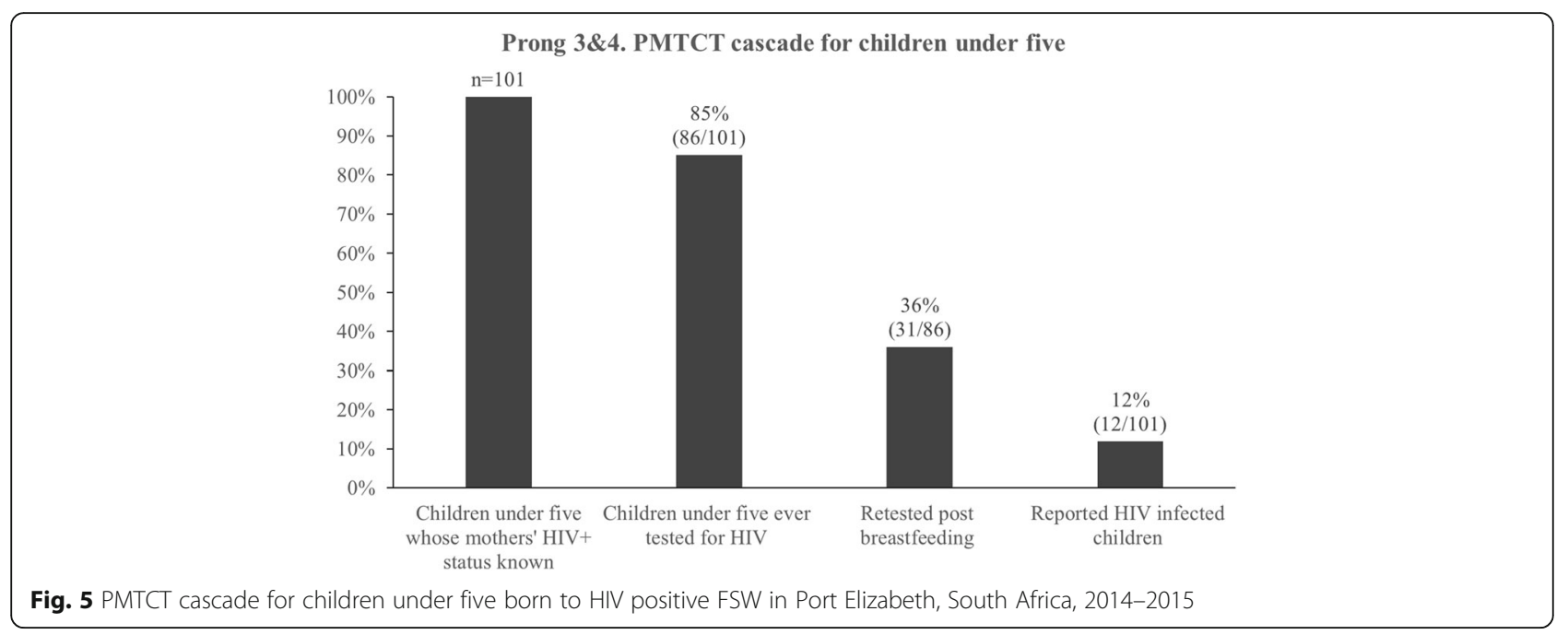

It also provides further evidence that programs that are successful for other women of reproductive age do not necessarily work for FSW due mainly to structural factors particular to FSW that limit their ability to access HIV prevention and treatment services [11]. Discriminatory practices may also play a role here, as other studies have found that insistence upon male partner attendance in ANC is one way of excluding FSW from care [32]. Additionally, among the few FSW who were pregnant and on ART at the time of study, none were virally suppressed indicating that even those on treatment may still have an elevated risk of MTCT [33, 34]. Specific programming efforts to improve ART coverage and viral load suppression tailored to FSW mothers are necessary.

Transmission risks among FSW may be higher than the national average given that $12 \%$ of the FSW who were known to be living with HIV prior to the study reported having at least one child living with HIV. Moreover, given that the reported retesting after breastfeeding is only $30 \%$, further undiagnosed MTCT cases likely exist.

The peer-led national sex worker strategy in South African provides a unique opportunity to address gaps in the PMTCT cascade for FSW [19]. Peer educators embedded within community-based outreach teams and central drop-in centers can help programs to identify FSW who are pregnant and support their early attendance in ANC services, support adherence of those on ART, support HIV testing services for children, find mother/infant pairs lost to follow up and support mothers in the treatment of infected children.

This study has limitations. First, the analysis relies on self-reported information for ART use, prior HIV diagnosis and children's HIV status, which are all subject to recall and social desirability bias. However, the high correlation of self-reported HIV diagnosis and testing results increases confidence in the accuracy of the self-report.
Furthermore, there is little reason to believe that the HIV infection status of the children would be overreported, however underreporting is possible, highlighting the importance for programmatic and research data that includes HIV testing of children of FSW. Restricting the analyses to women with children under five provided the possibility of placing the findings in the current PMTCT context but resulted in a smaller sample size that prevented the performance of more complex analyses. Lastly, the cross-sectional design limited our ability to assess temporal relationships, particularly of vertical transmission. Despite these limitations, clear MTCT risks were identified among the sample of mothers.

\section{Conclusion}

This study is one of the few to assess the level of engagement in the PMTCT cascade and to evaluate vertical transmission risks among FSW in South Africa and sub-Saharan Africa. The findings demonstrate that despite the successful implementation of PMTCT programs and tremendous achievement in the reduction of vertical HIV transmission in South Africa, FSW may experience poorer access and uptake of PMTCT services compared to other women of reproductive age. FSW have high HIV acquisition risks, high unmet needs in family planning, lower ART uptake during pregnancy and in postnatal periods and may be experiencing higher MTCT rates compared to the national average. Reinforcement of specific PMTCT programming for FSW is critical to improve the health outcomes for FSW and their children.

A French translation of this article has been included as Additional file 1.

A Portuguese translation of the abstract has been included as Additional file 2. 


\section{Additional files}

Additional file 1: Translation of this article into French. (PDF $469 \mathrm{~kb}$ )

Additional file 2: Translation of the abstract of this article into Portuguese. (PDF $107 \mathrm{~kb}$ )

\section{Abbreviations}

ANC: Antenatal care; ART: Antiretroviral treatment; CCU: Consistent Condom Use; FSW: Female Sex Workers; HIV: Human Immunodeficiency virus; IQR: Interquartile range; IUD: Intrauterine Device; MTCT: Mother-to-child Transmission of HIV; NMBM: Nelson Mandela Bay Metropolitan Municipality; PMTCT: Prevention of Mother-to-Child Transmission of HIV; PrEP: Preexposure Prophylaxis; RDS: Respondent Driven Sampling; SRHR: Sexual Reproductive Health and Rights; SSA: Sub-Saharan Africa; STI: Sexually Transmitted Infection; WHO: World Health Organization

\section{Acknowledgements}

We are grateful to the women who participated in the study for their time and for sharing their experiences with us. We also thank all the organizations and persons who were involved in the conceptualization and implementation of this study. The authors also thank the Johnson and Johnson for their donation of supplies to the women who participated in this study.

\section{Funding}

This study was funded by the MAC AIDS foundation. The implementation was conducted by the Human Sciences for Research Council (HSRC) and the TB/HIV Care Association (THCA) in collaboration with the Johns Hopkins University. This research has been facilitated by the infrastructure and resources provided by the Johns Hopkins University Center for AIDS Research, an NIH funded program (1P30Al094189), which is supported by the following NIH CoFunding and Participating Institutes and Centers: NIAID, NCI, NICHD, NHLBI, NIDA, NIMH, NIA, FIC, NIGMS, NIDDK, and OAR

The journal supplement is made possible by the generous support of the American People through the United States Agency for International Development (USAID) in partnership with United Nations Population Fund (UNFPA) and The Joint United Nations Program on HIV/AIDS (UNAIDS). The views expressed in this publication are solely the opinions of the authors and do not necessarily reflect the official policies of the USAID, UNFPA or UNAIDS, nor does mention of the department or agency names imply endorsement by the U.S. Government, UNFPA or UNAIDS.

\section{Availability of data and materials}

The data are owned by the partner institutions. Requests for data utilization should be sent to Sheree Schwartz at: sschwartz@jhu.edu.

\section{About this supplement}

This article has been published as part of BMC Public Health, Volume 19 Supplement 1, 2019: Effective Integration of Sexual Reproductive Health and HIV Prevention, Treatment, and Care Services across sub-Saharan Africa: Where is the evidence for program implementation? The full contents of the supplement, published as a joint collaboration between Reproductive Health and BMC Public Health, are available online at https://bmcpublichealth.biomedcentral.com/articles/supplements/volume-19-supplement-1 and https:// reproductive-health-journal.biomedcentral.com/articles/supplements/volume16-supplement-1

\section{Authors' contribution}

ShS, SB, NP-M, ZK, AL and MM conceptualized the study; ZK, MM, ShS, AL, NP-M, SK, HH and SB all supported implementation of the study. JOTR, ShS, AR and SK conducted the analyses. JOTR, ShS and SB drafted the manuscript and all authors contributed to the content of the manuscript. All authors have read and approved the final manuscript.

\section{Ethics approval and consent to participate}

The study was approved by the institutional review boards of Johns Hopkins School of Public Health and the Human Sciences Research Council in South Africa. All participants completed an informed consent to participate in the study.

\section{Consent for publication}

Not applicable.

\section{Competing interests}

The authors declare that they have no competing interests.

\section{Publisher's Note}

Springer Nature remains neutral with regard to jurisdictional claims in published maps and institutional affiliations.

\section{Author details}

${ }^{1}$ Department of Epidemiology, Key Populations Program, Center for Public Health and Human Rights, Johns Hopkins Bloomberg School of Public Health, 615 N Wolfe Street, Baltimore, MD 21205, USA. ${ }^{2}$ The TB/HIV Care Association, Cape Town, South Africa. ${ }^{3}$ The Human Sciences Research Council, Port Elizabeth, South Africa. ${ }^{4}$ Nelson Mandela Metropolitan University, Port Elizabeth, South Africa. ${ }^{5}$ The TB/HIV Care Association, Port Elizabeth, South Africa.

\section{Published: 29 May 2019}

\section{References}

1. UNAIDS. Global plan towards the elimination of new infections in children by 2015 and keeping mothers alive, 2011-2015. Geneva: UNAIDS; 2011.

2. World Health O. PMTCT strategic vision 2010-2015: preventing mother-tochild transmission of HIV to reach the UNGASS and millennium development goals. Geneva: WHO; 2010.

3. UNAIDS. On fast-track to an AIDS free- generation. Geneva: UNAIDS; 2016.

4. Health Do. National Consolidated guidelines for the Prevention of MotherTo-child transmission of HIV (PMTCT) and the management of HIV in Children, Adolescents and Adults. In: National Department of Health - South Africa. Pretoria: Department of Health in South Africa; 2014

5. UNAIDS: Prevention gap report. 2016

6. Schwartz SR, Baral S. Fertility-related research needs among women at the margins. Reprod Health Matters. 2015;23(45):30-46.

7. Baral S, Beyrer C, Muessig K, Poteat T, Wirtz AL, Decker MR, Sherman SG, Kerrigan D. Burden of HIV among female sex workers in low-income and middle-income countries: a systematic review and meta-analysis. Lancet Infect Dis. 2012;12(7):538-49.

8. Papworth E, Ceesay N, An L, Thiam-Niangoin M, Ky-Zerbo O, Holland C Dramé FM, Grosso A, Diouf D, Baral SD. Epidemiology of HIV among female sex workers, their clients, men who have sex with men and people who inject drugs in West and Central Africa. Int AIDS Soc. 2013;16(Suppl 3):18751.

9. Ngugi EN, Roth $E$, Mastin $T$, Nderitu MG, Yasmin S. Female sex workers in Africa: epidemiology overview, data gaps, ways forward. SAHARA J. 2012:9(3):148-53.

10. Shannon K, Goldenberg SM, Deering KN, Strathdee SA. HIV infection among female sex workers in concentrated and high prevalence epidemics: why a structural determinants framework is needed. Curr Opin HIV AIDS. 2014;9(2):174-82.

11. Shannon K, Strathdee SA, Goldenberg SM, Duff P, Mwangi P, Rusakova M, Reza-Paul S, Lau J, Deering K, Pickles MR, et al. Global epidemiology of HIV among female sex workers: influence of structural determinants. Lancet. 2015;385(9962):55-71.

12. Heckathorn DD, Wangroongsarb P, Thwing J, Eliades J, Satimai W, Delacollette C, Kaewkungwal J, Zhou G, Sirichaisinthop J, Sattabongkot J, et al. Respondent-driven sampling: a new approach to the study of hidden populations. Soc Probl. 1997;44(2):174-99.

13. Schwartz S, Lambert A, Phaswana-Mafuya N, Kose Z, Mclngana M, Holland C, Ketende S, Yah C, Sweitzer S, Hausler H, et al. Engagement in the HIV care cascade and barriers to antiretroviral therapy uptake among female sex workers in Port Elizabeth, South Africa: findings from a respondent-driven sampling study. Sex Transm Infect. 2016;93:290-96. sextrans-2016-052773.

14. Rao A, Baral S, Phaswana-Mafuya N, Lambert A, Kose Z, Mclngana M, Holland C, Ketende S, Schwartz S. Pregnancy intentions and safer pregnancy knowledge among female sex Workers in Port Elizabeth, South Africa. Obstet Gynecol. 2016;128(1):15-21.

15. Health RoSANDo: National HIV Counselling and Testing (HCT) Policy Guidelines: South Africa. 2010. 
16. Hamilton E, Bossiky B, Ditekemena J, Esiru G, Fwamba F, Goga AE, Kieffer MP, Tsague LD, van de Ven R, Wafula R, et al. Using the PMTCT Cascade to accelerate achievement of the global plan goals. J Acquir Immune Defic Syndr. 2017;75:S27-35.

17. Hofer CB, Egger M, Davies M-A, Frota ACC, de Oliveira RH, Abreu TF, Araújo $L E$, Witthlin BB, Carvalho AW, Cordeiro JR, et al. The cascade of care to prevent mother-to-child transmission in Rio de Janeiro, Brazil, 1996-2013: improving but still some way to go. Tropical Med Int Health. 2017;22(10): 1266-74.

18. Dionne-Odom J, Welty TK, Westfall AO, Chi BH, Ekouevi DK, Kasaro M, Tih PM, Tita ATN. Factors associated with PMTCT cascade completion in four african countries. AIDS Research and Treatment. 2016. https://doi.org/10. 1155/2016/2403936.

19. SANAC. The South African National Sex Worker HIV Plan, 2016-2019. Pretoria: South African National Aids Council (SANAC); 2016.

20. Dinh TH, Delaney KP, Goga A, Jackson D, Lombard C, Woldesenbet S, Mogashoa M, Pillay Y, Shaffer N. Impact of maternal HIV seroconversion during pregnancy on early mother to child transmission of HIV (MTCT) measured at 4-8 weeks postpartum in South Africa 2011-2012: a National Population-Based Evaluation. PLoS One. 2015;10(5):e0125525.

21. Bispo S, Chikhungu L, Rollins N, Siegfried N, Newell ML. Postnatal HIV transmission in breastfed infants of HIV-infected women on ART: a systematic review and meta-analysis, vol. 20; 2017.

22. Mugwanya KK, John-Stewart G, Baeten J. Safety of oral tenofovir disoproxil fumarate-based HIV pre-exposure prophylaxis use in lactating HIVuninfected women. Expert Opin Drug Saf. 2017;16(7):867-71.

23. Mugwanya KK, Hendrix CW, Mugo NR, Marzinke M, Katabira ET, Ngure K, Semiyaga NB, John-Stewart G, Muwonge TR, Muthuri G, et al. Pre-exposure prophylaxis use by breastfeeding HIV-uninfected women: a prospective short-term study of antiretroviral excretion in breast Milk and infant absorption. PLoS Med. 2016;13(9):e1002132.

24. WHO. Preventing HIV during Pregnancy and Breastfeeding in the context of PREP. Geneva; 2017.

25. SS S, Papworth E, Thiam-Niangoin M, Abo K, Drame F, Diouf D, Bamba A Ezouatchi R, Tety J, Grover E, et al. An urgent need for integration of family planning services into HIV care: The High Burden of Unplanned Pregnancy, Termination of Pregnancy, and Limited Contraception Use Among Female Sex Workers in Cote d'Ivoire TT. J Acquir Immune Defic Syndr. 2015;68(Suppl 2):S91-8.

26. Luchters S, Bosire W, Feng A, Richter ML, King'ola N, Ampt F, Temmerman M, Chersich MF. "A baby was an added burden": predictors and consequences of unintended pregnancies for female sex Workers in Mombasa, Kenya: a mixed-methods study. PLoS One. 2016;11(9):e0162871.

27. Chanda MM, Ortblad KF, Mwale M, Chongo S, Kanchele C, Kamungoma N, Barresi LG, Harling G, Barnighausen T, Oldenburg CE. Contraceptive use and unplanned pregnancy among female sex workers in Zambia. Contraception. 2017;96(3):196-202.

28. Lafort Y, Greener R, Roy A, Greener L, Ombidi W, Lessitala F, Skordis-Worrall J, Beksinska M, Gichangi P, Reza-Paul S, et al. Sexual and reproductive health services utilization by female sex workers is context-specific: results from a cross-sectional survey in India, Kenya, Mozambique and South Africa. Reprod Health. 2017;14(1):13.

29. Kost K, Lindberg L. Pregnancy intentions, maternal behaviors, and infant health: investigating relationships with new measures and propensity score analysis. Demography. 2015;52(1):83-111.

30. Hall JA, Benton L, Copas A, Stephenson J. Pregnancy intention and pregnancy outcome: systematic review and meta-analysis. Matern Child Health J. 2017;21(3):670-704.

31. Lindberg L, Maddow-Zimet I, Kost K, Lincoln A. Pregnancy intentions and maternal and child health: an analysis of longitudinal data in Oklahoma. Matern Child Health J. 2015;19(5):1087-96.

32. Beckham SW, Shembilu CR, Brahmbhatt H, Winch PJ, Beyrer C, Kerrigan DL Female sex Workers' experiences with intended pregnancy and antenatal Care Services in Southern Tanzania. Stud Fam Plan. 2015;46(1):55-71.

33. Mandelbrot L, Tubiana R, Le Chenadec J, Dollfus C, Faye A, Pannier E, Matheron S, Khuong M-A, Garrait V, Reliquet V, et al. No perinatal HIV-1 transmission from women with effective antiretroviral therapy starting before conception. Clin Infect Dis. 2015;61(11):1715-25.

34. Myer L, Phillips TK, Hsiao NY, Zerbe A, Petro G, Bekker LG, Mclntyre JA, Abrams EJ. Plasma viraemia in HIV-positive pregnant women entering antenatal care in South Africa. J Int AIDS Soc. 2015;18:20045.

Ready to submit your research? Choose BMC and benefit from:

- fast, convenient online submission

- thorough peer review by experienced researchers in your field

- rapid publication on acceptance

- support for research data, including large and complex data types

- gold Open Access which fosters wider collaboration and increased citations

- maximum visibility for your research: over $100 \mathrm{M}$ website views per year

At BMC, research is always in progress.

Learn more biomedcentral.com/submissions 